RERTATIE MIE MALLED

Campinas-SP, v.39, n.2, pp. 573-585, jul./dez. 2019

\title{
NOTAS SOBRE A HISTORICIDADE DE OS DIáRIOS DE EMILIO RENZI
}

\author{
NOTES ON HISTORICITY OF \\ OS DIÁRIOS DE EMILIO RENZI
}

\author{
Júlio Pimentel Pinto
}

\begin{abstract}
Resumo: Os três volumes editados de Los diarios de Emilio Renzi ora assumem uma estética do fragmento e apontam para o instantâneo, ora desenham uma sequência linear de leituras de formação; ora tratam de um personagem só, o autor, ora negam a dimensão autoral e autobiográfica e buscam registros das memórias coletivas - históricas ou literárias. Marcados por uma vontade fundadora e por inúmeras incertezas e hesitações, Los diarios de Emilio Renzi sondam as possibilidades e os limites da construção de um diário e reúnem a percepção do interior à do exterior, o desenho de uma unidade impossível à representação multiplicada de si. Em todas as circunstâncias, porém, dialogam com a experiência história, indicam percursos genealógicos da obra de Ricardo Piglia e, para representá-la, constroem estratégias singulares de deslocamento e distanciamento.

Palavras-chave: Ricardo Piglia, diário, deslocamento.
\end{abstract}

\begin{abstract}
The three published tomes of Los diarios de Emilio Renzi sometimes externalize an aesthetic of fragment and indicate the moment and sometimes draw the profile of a reader in linear formation; sometimes focus only one character, the author, sometimes deny any authorial or autobiographical dimension and search registries of collective historical or literary memories.

Marked by founding wishes, uncertainties and hesitations, Los diarios de Emilio Renzi probes the limits and possibilities of a personal diary construction and brings together the self and the person perception, the design of an impossible unity and the multiplied representation of oneself. However, in all circumstances they dialogue with historical experience, show genealogical paths of Ricardo Piglia's works and build strategies of displacement and distance.
\end{abstract}

Keywords: Ricardo Piglia, Diary, Displacement.

1 Departamento de História, Universidade de São Paulo (USP): <juliop@uol.com.br>. 
A vida não se divide em capítulos”, diz Emilio Renzi (2019, p. 7) na frase que abre Os anos felizes, segundo volume de seus diários. Em seguida, explica:

Sempre me intrigou o modo irreal mas matemático em que ordenamos os dias. [...] Falo por mim, disse, que escrevo um diário, e os diários só obedecem à progressão dos dias, meses e anos. Não há outra coisa que possa definir um diário, não é o material autobiográfico, não é a confissão íntima, nem sequer é o registro da vida de quem o escreve que o define; simplesmente, disse Renzi, é a ordenação do escrito pelos dias da semana e os meses do ano. Só isso, disse satisfeito (PIGLIA, 2019, p. 7).

Entre as muitas informações e constatações que o trecho oferece, uma salta aos olhos: a relação direta e profunda entre o diário e o tempo. Só existe diário se houver menção a datas. Não é o Tempo "substância formadora dos homens” de que falou Borges. É o tempo dividido, calculado e medido dos dias, meses e anos - o tempo que, no seu caráter convencional, permite conexões, reúne experiências dissimilares, regula relações, define sequências e encadeamentos entre temporalidades. É o tempo, matéria essencial da memória: se buscado e reencontrado, permite balizar o que foi vivido. E é o tempo, matéria essencial da história: se analisado e interpretado, submetido ao crivo da crítica, tensionado pelo diálogo com outras temporalidades, deixa-nos entrever a vida individual e coletiva das gentes.

Na afirmação de Renzi, no entanto, talvez haja algo de ilusionismo: as anotações lançadas num caderno não provocam, por si sós, esse movimento de combinação entre temporalidades. ${ }^{2}$ Elas limitam-se a elencar eventos, orientados pela distribuição dos dias. O olhar que compõe as relações, inventa sequências e cria significados para esses eventos é de outro tempo: é do presente. É um olhar distanciado, familiar, porém estranho à experiência vivida. Ou, em outros termos, as anotações nos cadernos seguem a ordenação arbitrária do calendário e permanecem desconexas entre si, enquanto as ordenações apresentadas nos diários publicados respeitam o olhar historicizador que aglutina e produz lógicas.

2 Por uma questão de praticidade, adoto, neste texto, a distinção entre "cadernos" - o material acumulado ao longo dos anos e hoje conservados na Universidade de Princeton e "diários" - o conjunto de três volumes editados e publicados de 2015 a 2017. 
A história e a historicidade de Os diários de Emilio Renzi estão mais na edição impressa do que nos arquivos de Princeton.

II.

Os cadernos manuscritos e os diários impressos são fragmentários. Entretanto, os diários respondem e correspondem à lógica de um autor - cujo nome por ora não interessa. Eles derivam de um conjunto de intervenções no material difuso e guardado atabalhoadamente em caixas: releitura, seleção, exclusão, reescritura. Mantém-se a estética do fragmento, inevitável nos cadernos, e acrescentam-se linearidade e sequenciamento, mas não são a linearidade e o sequenciamento determinados pelo calendário.

Aquele que revisita os cadernos para publicá-los situa-se no tempo, reconhece sua condição de "laboratório do escritor" eage no presente "sobre o fundo de uma temporalidade que nos precede" (DIDI-HUBERMAN, 2017, p. 15). Nenhum passado, porém, ressurge puro no presente, não há imanência, há genealogia e transformação: o longínquo é sintetizado no próximo, as intermitências e descontinuidades assumem outra feição; elas, agora, não resultam da progressão dos dias no calendário, e sim da necessidade e urgência dos significados que se pretende impor à sucessão das anotações. A dimensão ocasionalmente dramática presente nos cadernos é substituída pela cronicidade dos diários (p. 85). Crônica, não custa lembrar, já na etimologia é representação do tempo, é olhar que recorre à agulha do instante para promover costura entre experiências diversas de tempos afastados.

Georges Didi-Huberman observa que a composição de um diário é essencialmente desafiadora porque

É terrivelmente difícil apresentar claramente a que estamos nós mesmos
direta e vitalmente expostos. Como escrever o que sofremos, como construir
um logos - ou se fazer uma categoria de espécie, uma ideia, um eidos - com seu
próprio pathos do momento? (DIDI-HUBERMAN, 2017, p. 27).

Como construir uma inteligência ativa, um princípio de si, ante a tensão do momento vivido? A solução de Piglia aparece, por exemplo, quando comenta o diário de Gombrowicz, em "El escritor como lector", texto incluído na Antología personal. Num jogo de espelhamento, ao falar do diário do escritor polonês, Piglia (2015a, posição 1.222) fala de seu próprio diário e define a ambos como "a história de suas leituras". Mais: "O 
Diário [de Gombrowicz] é isso, uma espécie de experimentação contínua com a experiência, com a forma, com a escritura" (posições 1.217-1.222). Não pode passar despercebido que as duas respostas aludam às anotações transfiguradas para a versão que chegará aos leitores: o diário publicado, público, em tensão com o espaço do privado e num distanciamento calculado (posições 1.197-1.207).

No mesmo ensaio, Piglia desenvolve uma longa reflexão - que deriva tanto de Gombrowicz quanto de Borges - sobre a ideia de literatura como "um modo de ler", modo que define gêneros, inventa precursores é, na definição de Alberto Giordano (2005, p. 212), uma "decifração como captação sem restos dos sentidos secretos" e é infalivelmente histórico e social: passado revisitado é passado transformado. Ou, dito de outra maneira, toda leitura é um exercício de história, uma combinação entre temporalidades múltiplas, uma circulação entre estratos do tempo.

Revisitar a experiência, testá-la na forma e na escritura do relato: os cadernos dependem do calendário, mas os diários dependem da construção de sua historicidade que, por sua vez, é necessariamente exposta. Compõem-se os diários a partir dos cadernos para revelar aos leitores - dada sua dimensão pública - uma possibilidade de passado, para exigir dos leitores que participem da (re)invenção de passados, que tomem posição diante dos muitos passados possíveis. Num registro de base autobiográfica, afinal, o leitor "completa o círculo da sua expressividade" (PIGLIA, 2017b, p. 354).

É certo que a edição dos diários de Renzi corresponde menos a um esforço de construção da memória ou a um conjunto de elementos destinados à futura composição de uma autobiografia, e mais a uma tentativa de Piglia de constituir um guia ou um protocolo de leitura de sua obra ficcional e crítica. Por isso, o passado autenticado pela ilusão de verdade trazida pela ordenação posterior dos fragmentos acaba por ser uma moldura na qual o leitor - esse incessante criador de gêneros, lógicas e textos - encaixa o que lê. Por isso, a historicidade dos diários é peça fundamental na máquina de leitura dos demais escritos piglianos.

\section{III.}

Uma moldura para a leitura. Diferentemente do que ocorre nas anotações privadas, talvez secretas, dos cadernos acumulados ao longo da vida, num diário público a "situação comunicativa" com o leitor exige um enquadramento (MARTENS, 1985, p. 33). Quem o faz é o autor, seja ele 
real ou fictício. Inevitável, então, que se faça a pergunta, mesmo sabendo que ela é óbvia e que sua resposta é enigmática: Quem é o autor?

Lorna Martens afirma que o "diarista" - aquele que escreve as anotações - tem limitado controle sobre o material que produz, seja ele um "diarista real” ou um "diarista fictício”. Já o autor de um diário-fictício tem

[...] absoluto controle: ele pode criar um enredo. Ele também pode recorrer às técnicas literárias que quiser: leitmotiv, alegoria, ironia. [...] A estrutura do diário pode ser explorada para ilustrar e reforçar a tese do romance, [...] [para dar-lhe] expressividade (MARTENS, 1985, p. 34). ${ }^{3}$

Michel Butor, por exemplo, chega mesmo a desrespeitar a progressão dos dias, meses e anos - aquela que, para Renzi, define um diário -, e altera a ordem e o sequenciamento das entradas no ficcional L'emploi du temps. Os diários de Emilio Renzi, porém, não são um romance-diário, nem um "diário real". Sua escrita "coloca-se [...] desde o início como uma 'escritura da vida', uma ficcionalização da vivência como direcionada à obra” (BERGONZONI, 2019, p. 250). Ou: desenvolve-se em "um regime de construção e de validação estética” (KOHAN, 2017, p. 263). Ou ainda:

[...] uma estetização do real, [que] devolve ao mundo não apenas sua imagem distorcida, mas também uma especulação empírica sobre o real e sobre a escrita: uma específica proposta estética em que escrita e real não são coisas diversas (FUKS, 2016, p. 12).

Os diários circulam livremente pelos dois polos e valem-se dos recursos que ambos lhe franqueiam. Duplicam, dessa forma, a moldura. Por um lado, sustentam-se na crença do leitor de que haja uma vida efetivamente vivida e transposta para as anotações, um referente real de certa forma responsável pelos significados identificáveis no texto. $\mathrm{O}$ nome "Ricardo Piglia" impresso nas capas contribui bastante para isso, ao lado das incontáveis referências aos cadernos, feitas na ficção e na crítica de Piglia. Por outro lado, o nome de Renzi também está na capa e surge como o responsável pelos diários; a narração dos três volumes flutua

3 "[...] has absolute control. For example the author can create a plot. he can also use whatever other literary techniques he wants - leitmotifs, allegory, irony. [...] the diary's structure itself can be exploited to illustrate and reinforce the novel's thesis [...] it can become 'expressive." A autora exemplifica com os casos dos "romances-diários" de Max Frisch (Stiller, 1954), Michel Butor (L'emploi du temps, 1956) e Doris Lessing (Golden Notebook, 1962). 
entre a primeira e a terceira pessoas; textos ficcionais alternam-se com anotações do cotidiano, numa "exasperação" das "interferências e [dos] revezamentos de gêneros textuais e vozes enunciativas ensaiadas por Piglia ao longo de sua obra" (GÁRATE, 2019, p. 238). Em suma, a questão "Quem diz eu?" não é apenas retórica, nem "o Eu é todo o espetáculo" (PIGLIA, 2017b, p. 354).

O espetáculo está na antinomia, no jogo ambíguo de mascaramento e centralidade da autoria, na troca da "autocontemplação" pela “autotransformação” (KOHAN, 2017, p. 264). O espetáculo está na "presença de uma segunda voz na narrativa, amplamente associada à voz do autor" (MARTENS, 1985, p. 34) - inclusive porque a ficcionalização das anotações do dia a dia "intensifica o caráter absurdo e claustrofóbico dos registros, no qual a perspectiva é estritamente limitada” (p. 192). Trago a questão para o que me interessa de imediato: a intromissão da ficcionalidade e a decorrente combinação das duas vozes ampliam e, mais importante, deslocam a perspectiva. Poderia dizer, retornando a Didi-Huberman, que a questão da autoria transforma-se numa observação sobre algo que a transcende: a "tomada de posição". Autor uno ou plural, desejoso ou não de "ser outro" (COUTURIER, 1995, p. 197), alegre pela multiplicação possível de si mesmo, ele assume uma "posição histórica diante das coisas" (DIDI-HUBERMAN, 2017, p. 69), dispõe-se a "coletar o passado para prefigurar o futuro" (MARTENS, 2011, posição 1.844) e o presente, a montar e remontar todos os passados da memória, a identificar singularidades e repetições no movimento do tempo, a liquidar o isolamento de cada temporalidade e estabelecer vínculos e sentidos mais amplos para o real vivido.

\section{IV.}

Deslocamento. Ao nos deslocarmos, estabelecemos uma relação significativa com o passado - justamente porque primeiro reconhecemos e em seguida alteramos nossa posição. David Lowenthal (1998, p. XV-XVI) alerta que o passado "está em toda parte", mas é "uma terra estrangeira": mesmo se tivermos dificuldade de aceitar esse estrangeirismo, alcançamos alguma compreensão da experiência vivida a partir dos resíduos que ela nos legou; articulamos o conforto da percepção guiada pelo presente ao estranhamento proporcionado pelo passado; despertamos "a surpresa para fazer nascer o espírito de interrogação, depois de observação, depois a liberdade de julgamento" (BLANCHOT, 1969, p. 534). Logo, deslocamento 
como capaz de criar o enigma, instigar a dúvida e sugerir interpretações; como correlato de distanciamento ou estranhamento, também formas de variação da perspectiva.

Deslocar, distanciar, estranhar são estratégias narrativas - ou artísticas -; afinal, a

[...] arte é [...] capaz de mostrar todas as coisas como outras coisas e, sob a familiaridade, o insólito, e naquilo que é, o que não conseguiria ser. [...]

É precisamente esse distanciamento [...], pelo efeito de estranhamento (BLANCHOT, 1969, p. 534). 4

A "representação estranha" altera a experiência do passado e lhe atribui novo significado, substituindo o original, inalcançável no presente:

A nova imagem artística [...] não representa apenas a coisa; ela a mostra sob a luz de um dia longínquo, transformada pela força do longínquo, diferente de como nos costumava parecer, e subtraída, desde então, daquela aparência usual de familiaridade em que acreditávamos ver sua natureza verdadeira e sua substância eterna (BLANCHOT, 1969, p. 534). ${ }^{5}$

Sigo um pouco mais com Blanchot para ressaltar o que é efeito do distanciamento e, simultaneamente, da representação por ele gerada: a restauração da experiência:

A imagem, capaz desse efeito de estranhamento, consuma então uma espécie de experiência, mostrando-nos que as coisas talvez não sejam o que elas são, que depende de nós vê-las de outra forma e, por essa fresta, torná-las imaginativamente outras e, depois, outras ainda, realmente bem diferentes (BLANCHOT, 1969, p. 534). ${ }^{6}$

Não há paradoxo, e sim propósito cognitivo: nos distanciamos, produzimos o estranhamento para nos reaproximarmos da experiência vivida sem banalizá-la (GINZBURG, 2001, p. 36). Piglia (2017b, pp. 240, 16

4 "[...] l'art [...] est capable en toutes choses de désigner autre chose et, sous le familier, l'insolite et, dans ce qui est, ce qui ne saurait être. [...] C'est précisément cet écart [...] par l'effet d'étrangeté".

5 "La nouvelle image artistique [...] ne représente pas seulement la chose, mais elle nous la montre sous un jour lointain, transformée par la force du lointain, autre qu'elle n'avait l'habitude de nous apparaître et soustraite, dès lors, à cette apparence de familiarité usuelle où nos croyions voir sa vraie nature et sa substance éternelle."

6 "L'image, capable de l'effet d'étrangeté, réalise donc une sorte d'expérience, en nous montrant que les choses ne sont peut-être pas ce que qu'elles sont, qu'il dépend de nous les voir autrement et, par cette ouverture, de les rendre imaginairement autre, puis réellement tout autres."

Remate de Males, Campinas-SP, v.39, n.2, pp. 573-585, jul./dez. 2019 - 579 
e 18, respectivamente) diz que "gostaria de escrever sobre mim mesmo em terceira pessoa”, observa sua vida "do alto de um mirante" e seus diários, "do lado de fora, distanciado, e me vejo como se eu fosse outra pessoa (sempre mais jovem)". Note-se que a voz varia juntamente com a temporalidade - "me vejo [...] mais jovem" -, o que reafirma o gesto historicizador que acompanha o deslocamento e a disposição de compreender (e fazer compreender) o passado por meio de sua remontagem. Na trilha de Blanchot, Didi-Huberman (2017, pp. 63-64) insiste na relação: "O objetivo do efeito de distanciamento é extrair dos processos representados seu gestus social fundamental [que resulta de uma] técnica: a historicização que é de extrema importância”.

\section{V.}

Historicizar, interpretar. Na voz de Renzi, "As definições, as decisões deveriam importar, mas precisam ser configuradas, historicizadas, contadas como se acontecessem com outros. Ilusão de viver em terceira pessoa" (PIGLIA, 2017b, p. 215). Vida em terceira pessoa, minha e distante, própria eestranha, contada a partirda "concepçãodequeosacontecimentos da vida devem ser colocados em perspectiva - reescritos, em suma - pelo autor que se olha como se fosse um personagem" (BERGONZONI, 2019, p. 254).

Reescrever o passado. Reconhecer o tempo vivido e compreendê-lo por meio de seus desdobramentos em outras temporalidades e de seus efeitos no presente; perceber seu movimento de repetições e variações. Logo no início de Anos de formação, o narrador explica:

A experiência, ele percebera, é uma multiplicação microscópica de pequenos acontecimentos que se repetem e se expandem, sem conexão, dispersos, em fuga. Sua vida, ele compreendera, era dividida em sequências lineares, séries abertas que remontavam ao passado distante: incidentes mínimos, estar sozinho num quarto de hotel, ver seu rosto num instantâneo, entrar num táxi, beijar uma mulher, levantar os olhos da página e dirigi-los à janela, quantas vezes? Esses gestos formavam uma rede fluida, desenhavam um percurso - e desenhou um mapa de círculos e cruzes num guardanapo -, digamos que o percurso da minha vida seria assim, disse. A insistência dos temas, dos lugares, das situações é o que eu quero - falando figuradamente - interpretar. Como um pianista que improvisa, sobre um frágil standard, variações, mudanças de ritmo, harmonias de uma música esquecida, disse, e se ajeitou na cadeira (PIGLIA, 2017b, p. 16). 
A vida como uma "rede fluida" - "percebida”, "compreendida", "interpretada" por Emilio Renzi. Vida que pode ser contada de diferentes maneiras, conforme se valorize uma ou outra sequência, feche-se uma série para que outra se abra, desenhe-se o passado esquematicamente num guardanapo ou o figure na improvisação criada a partir de um de seus temas. Renzi ajeita-se na cadeira, confortável após declarar a historicidade de sua reconstrução da experiência. Mas em que regime de historicidade conformam-se Os diários de Emilio Renzi?

Relembro: a princípio, um diário presta-se para registrar a experiência real (rotinas e discretos rituais pessoais, amores, medos, desejos, conflitos, escolhas do cotidiano) e a experiência estética, não menos real: leituras, filmes, exposições, reflexões. Embora redigido na urgência do presente, um diário, quando relido, parece guardar o caminho de nossa formação e apontar o passado - um passado lato e abstrato - como tempo predominante. O passado oferece exemplos, mantém-se constante, relaciona-se apenas consigo mesmo, explica o presente e o futuro, impondo-se a outras temporalidades: nesse regime passadista, a história manifesta-se, lembra Koselleck (2006, p. 43), como "a testemunha dos tempos, a luz da verdade, a vida da memória, a mensageira da velhice" e as coisas parecem acontecer "no tempo".

Ao avaliar, a partir do diário de Brecht, a dimensão íntima que resulta dessa definição, Didi-Huberman (2017, pp. 26-27) amplia a compreensão da revisitação do passado provocada por meio da leitura de diários e demonstra a impossibilidade de resumi-la a esse passadismo:

\footnotetext{
Se a "consciência de si" é aí constantemente obrigatória, nem por isso a pura relação de si a si mesmo é aí visada [...]. Se a intimidade aí se exprime, não é tampouco que ela procure seu "refúgio matricial": ao contrário, ela não procura senão uma "forma aberta" capaz de romper as barreiras entre o privado e a história, a ficção e o documento, a literatura e o resto. Se há mesmo uma "gênese de si" no trabalho, esta não procura "descer na intimidade do indivíduo", como escreve Pierre Pachet, senão "para separá-lo de si mesmo, para colocá-lo em relação consigo mesmo por meio do que há de mais coletivo, de mais universal, de mais impessoal - a linguagem".
}

"Consciência de si” e de seu tempo são adventos da modernidade, em que a dimensão do privado inevitavelmente se comunica com a do coletivo, e a linguagem torna-se território capaz de articular experiências diversas e compartilhadas, onde "conceitos antitéticos se coordenam mutuamente no tempo", provocando "uma tensão temporal", "um futuro deslocamento" do espaço da experiência (KOSELLECK, 2006, p. 197). As anotações nos 
cadernos são fragmentos do passado, e nelas o autor dos diários imerge, "ultrapassando suas próprias vivências e recordações, conduzido por perguntas". Ele "movimenta-se em dois planos" (p. 305), mantendo-se deslocado e estranho a ambos. Assim percebe sua experiência num "grau de generalidade mais elevado" e, afinal, a experiência confina-se com

[...] o passado atual, aquele no qual acontecimentos foram incorporados e podem ser lembrados. [...] na experiência de cada um [...] é conservada uma experiência alheia. Nesse sentido, a história é desde sempre concebida como conhecimento de experiências alheias (KOSELLECK, 2006, pp. 307, 309-310).

O regime de historicidade em questão, portanto, não é passadista, nem um diário supõe o passado como "mestre da vida". Os diários de Emilio Renzi articulam passado, presente e futuro, este expresso numa categoria formal similar e contraposta à de experiência: a expectativa - no caso, a expectativa inúmeras vezes mencionada de tornar-se escritor. É essa historicidade que confere a unidade possível ao conjunto de fragmentos, contém a dispersão sem determinar rumo único de representação ou de leitura, mantém a produtiva "hesitação, a bem da verdade uma ambiguidade, em relação à forma fragmentária ou a uma forma totalizante" (BERGONZONI, 2019, p. 259). Uma historicidade fundada na semântica dos tempos históricos.

\section{VI.}

A entrada do domingo, 29 de setembro de 1968, registra que o narrador obteve, a preço alto, "o volume das cartas de Pavese" (PIGLIA, 2019, p. 72). Impressionado pela "contingência” e, ao mesmo tempo, pelos "vazios" da escrita da correspondência que lê, ele se pergunta: "O que procuro?”. A resposta é rápida e idêntica à que dá a muitas outras questões que levanta ao longo dos três volumes: "descobrir por que ele escreve", descobrir por que se escreve. A pergunta e a resposta levam-no a reconhecer a importância dos cadernos: "Durante anos foi - ainda é o único lugar em que eu podia me sustentar numa decisão delirante”, a de ser escritor (p. 72). E o narrador relata uma espécie de epifania ou de alucinação:

Vi tudo isso - vi quase psicoticamente minha vida inteira já vivida - num instante daquela tarde, sentado no piso de lajotas do corredor, com as costas apoiadas na parede, escrevendo palavras furiosas num caderno. Devo ter pensado: "Se eu escrever aqui o que quero viver - e não estupidamente só aquilo que vivo -, 
poderei depois viver o que escrevi como um oráculo realizado". Assim liguei para sempre escrita e vida (PIGLIA, 2019, p. 72).

A passagem resume, de forma intensa e sintética, o fato de que os diários não falam só do passado; eles dialogam incessantemente com outras temporalidades: Os diários de Emilio Renzi conformam a genealogia da obra de Piglia e são mesmo definidos pelo tempo, mas não, como tentou nos iludir o narrador da abertura de Os anos felizes, pela progressão linear - logo passadista -, obrigatória e artificial de dias, meses e anos. Ou, como ele próprio admite páginas à frente,

\footnotetext{
É insensato acreditar que a vida se divide em capítulos, ou em décadas, ou em segmentos definidos, tudo é mais confuso, há cortes, interrupções, passagens, fatos decisivos que chamaria de contratempos, porque produzem marchas e contramarchas na temporalidade pessoal (PIGLIA, 2019, p. 14).
}

Os diários estruturam-se por meio dos "contratempos" e, nesses contratempos, revelam a historicidade que os percorre, os unifica e que se manifesta em toda representação do passado - histórica ou ficcional. Recorrem a um regime de historicidade que trabalha "disjunções e conjunções de formas de temporalidade: interações, imbricações, ocultamentos, entrechoques, defasagens, descolamentos [...] experiências do tempo" (HARTOG, 2013a, p. 179). Fazem literatura em diálogo ininterrupto com a história, recuperando e ressignificando experiências. Até porque Renzi conhecia muito bem a porosidade das fronteiras entre história e ficção e podia afirmar, sem qualquer temor: "Nunca me preocupei com a ideia de que a literatura afasta da experiência, porque para mim as coisas se passaram ao contrário: a literatura construía a experiência” (PIGLIA, 2019, p. 72).

\section{$\overline{\text { REFERENNCIAS }}$}

BERGONZONI, Gisela. Autobiografias alheias: sobre Barthes e Piglia. In: FELIPPE, Eduardo Ferraz (Org.). Só se perde o que realmente não se teve: leituras e diálogos com Ricardo Piglia. Rio de Janeiro: Metanoia, 2019.

BLANCHOT, Maurice. L'entretien infini. Paris: Gallimard, 1969.

BUTOR, Michel. L’emploi du temps. Paris: Éditions du Minuit, 1995[1956].

COUTURIER, Maurice. La figure de l'auteur. Paris: Seuil, 1995. 
DIDI-HUBERMAN, Georges. O olho da história. Vol. I. Quando as imagens tomam posição. Trad. Cleonice Paes Barreto Mourão. Belo Horizonte: Editora da UFMG, 2017.

FUKS, Julián. História abstrata do romance. Tese (Doutorado em Teoria Literária e Literatura Comparada) - Universidade de São Paulo. São Paulo, 2016.

GALLON, Stéphane. Michel Butor: l'emploi du temps dans L'emploi du temps. Rennes: Presses Universitaires de Rennes, 2016.

GÁRATE, Miriam. Notas de trabalho: a propósito de Los diarios de Emilio Renzi. In: FELIPPE, Eduardo Ferraz (Org.). Só se perde o que realmente não se teve: leituras e diálogos com Ricardo Piglia. Rio de Janeiro: Metanoia, 2019, pp. 221-245.

GINZBURG, Carlo. Olhos de madeira: nove reflexões sobre a distância. Trad. Eduardo Brandão. São Paulo: Companhia das Letras, 2001.

GIORDANO, Alberto. Modos del ensayo: de Borges a Piglia. Rosário: Beatriz Viterbo, 2005.

HARTOG, François. Experiências do tempo: da história universal à história global. História, histórias, Brasília (UnB), v. 1, n. 1, 2013a, pp. 164-179.

HARTOG, François. Regimes de historicidade: presentismo e experiências do tempo. Trad. Andréa Souza de Menezes et al. Belo Horizonte: Autêntica, 2013b.

KOHAN, Martín. Alter ego: Ricardo Piglia y Emilio Renzi: su diario personal. Revista Landa, v. 4, n. 2, 2017, pp. 261-272.

KOSELLECK, Reinhart. L'expérience de l'histoire. Paris: Gallimard, 1997.

KOSELLECK, Reinhart. Futuro passado: contribuição à semântica dos tempos históricos. Trad. Wilma Patrícia Maas e Carlos Almeida Pereira. Rio de Janeiro: Contraponto/ PUC-Rio, 2006.

KOSELLECK, Reinhart. Estratos do tempo: estudos sobre história. Rio de Janeiro: Contraponto, 2014.

LOWENTHAL, David. The Past is a Foreign Country. Cambridge: Cambridge University Press, 1985.

LOWENTHAL, David. Como conhecemos o passado. Trad. Lúcia Haddad. Projeto História- Trabalhos da memória, São Paulo (Programa de Estudos Pós-Graduados em História da PUC-SP), n. 17, nov. 1998, pp. 63-201.

MARTENS, Lorna. The Diary Novel. Cambridge: Cambridge University Press, 1985.

MARTENS, Lorna. The Promise of Memory: Childhood Recollection and Its Objects in Literary Modernism [e-book]. Cambridge: Harvard University Press, 2011. 
PIGLIA, Ricardo. Antología personal [e-book]. Buenos Aires: Fondo de Cultura Económica, 2015a.

PIGLIA, Ricardo. Los diarios de Emilio Renzi. Vol. 1. Años de formación. Barcelona: Anagrama, 2015b.

PIGLIA, Ricardo. Los diarios de Emilio Renzi. Vol. 2. Los años felices. Barcelona: Anagrama, 2016.

PIGLIA, Ricardo. Los diarios de Emilio Renzi. Vol. 3. Un día en la vida. Barcelona:Anagrama, 2017 .

PIGLIA, Ricardo. Os diários de Emilio Renzi. Vol. 1. Anos de formação. Trad. Sérgio Molina. São Paulo: Todavia, 2017b.

PIGLIA, Ricardo. Os diários de Emilio Renzi. Vol. 2. Os anos felizes. Trad. Sérgio Molina. São Paulo: Todavia, 2019.

Recebido: 6/o6/2019

Aceito: 18/09/2019

Publicado: 25/11/2019

Remate de Males, Campinas-SP, v.39, n.2, pp. 573-585, jul./dez. 2019 - 585 